\title{
Superficial Middle Cerebral Vein
}

National Cancer Institute

\section{Source}

National Cancer Institute. Superficial Middle Cerebral Vein. NCI Thesaurus. Code C33664.

A vein that runs along the fissure of Sylvius to the cavernous sinus on the lateral surface of the brain and connects to the superior sagittal and transverse sinuses. 